Rios, S., Viana da Fonseca, A. and Baudet, B. (2012). The effect of the porosity/cement ratio on the compression behaviour of cemented soil. Journal of Geotechnical and Environmental Engineering, 138(11), 1422-1426, doi: 10.1061/(ASCE)GT.1943-5606.0000698

http://ascelibrary.org/doi/abs/10.1061/\%28ASCE\%29GT.1943-5606.0000698

\title{
THE EFFECT OF THE POROSITY/CEMENT RATIO ON THE COMPRESSION OF CEMENTED SOIL
}

Sara Rios, D.Sc.

Research fellow, University of Porto, Portugal

António Viana da Fonseca, D.Sc.

Associate Professor, University of Porto, Portugal

Béatrice Anne Baudet, Ph.D.

Assistant Professor, University of Hong Kong; formerly University College London, U.K.

Key words: soil-cement, porosity/cement ratio, normal compression line, isotropic compression

Contact Address:

Dr. Béatrice Anne Baudet

Department of Civil Engineering,

University of Hong Kong

Pokfulam Road

Hong Kong

E-mail: baudet@hku.hk 


\begin{abstract}
The compression behavior of an artificially cemented soil was analyzed by means of the adjusted porosity/cement ratio proposed using a correlation established in the recent literature. It was found that for each value of this parameter, defined as the ratio of porosity to the volumetric cement content, there is a unique Normal Compression Line (NCL). The NCLs of the cemented specimens for each adjusted porosity/cement ratio do not converge with the NCL of the uncemented silty sand at large stresses, but reach a line parallel to it, the lowest the adjusted porosity-cement index, the further the NCL of the cemented sand from the NCL of the uncemented sand.
\end{abstract}




\section{INTRODUCTION}

The improvement of soil characteristics by using cement is a generally economical and satisfying method that is used worldwide in pavement base layers, slope protection for earth dams, as a base layer to shallow foundations and to prevent liquefaction (Catton, 1962; Ingles and Metcalf, 1972; Dupas and Pecker, 1979; Porbaha et al., 1998; Thomé et al., 2005). The rules for designing cemented soil however are still predominantly empirical. In cement admixed clay, it is recognized that the strength is governed by the water and cement contents, and the ratio of clay-water content to cement content is generally used as a determining parameter (Miura et al., 2001; Horpibulsuk et al., 2005). In cemented sands however, there is no such recognized parameter. The porosity appears to be important, especially when specimens are molded in unsaturated conditions where most voids are not filled with water (Clough et al., 1981; Consoli et al., 2000; Rotta et al., 2003). Consoli et al. (2007) analyzed the effect of cement dosage, also an important parameter, on the behavior of unsaturated artificially cemented soils by using a porosity/cement ratio index. This index, which corresponds to the ratio of the soil porosity to the volumetric cement content $\left(n / C_{i v}\right)$, was shown to govern the unconfined compression strength and to a certain extent the shear modulus of the improved soil (Consoli et al., 2007; Consoli et al., 2009). For example, a unique relationship between the unconfined compression strength and the porosity/cement ratio amplified by an exponent $\xi$ specific to the soil could be found for a variety of soils, with $\xi$ equal to 1.00 for a uniform sand from Brazil (Osorio sand; Consoli et al., 2009; Viana da Fonseca et al., 2009), $\xi$ equal to 0.28 for a well graded residual soil from Brazil (Botucatu residual sandstone; Consoli et al., 2007), and $\xi$ equal to 0.21 for the Portuguese Porto residual soil from granite - the soil used herein (Consoli et al., 2011 - in press). In the following, the value $\left(\mathrm{n} / \mathrm{C}_{\mathrm{iv}}{ }^{\xi}\right)$ will be referred to as adjusted porosity-cement index. This note extends that work to the compression behavior of 
the improved Porto residual soil by examining the response to isotropic compression of specimens prepared at two given dosages, where a dosage corresponds to a fixed adjusted porosity-cement index but the cement content can vary.

\section{TESTING MATERIAL AND PROCEDURES}

\section{Material}

The host soil is a well graded non-plastic silty sand derived from weathered Porto granite that is abundant in Northern Portugal (Viana da Fonseca et al., 2006). The soil, kept consistent throughout the study, is classified as SM in the Unified Soil Classification System (ASTM, 1998). The density of the solids was determined as 2.72 . The silty sand has an effective diameter $\mathrm{D}_{50}$ equal to $0.25 \mathrm{~mm}$, and uniformity and curvature coefficients of 113 and 2.7 respectively (Table 1). Modified Proctor compaction tests were performed, and the maximum dry and optimum water content obtained were $18.5 \mathrm{kN} / \mathrm{m}^{3}$ and $13 \%$, as illustrated in Figure 1. A high strength Portland cement (CEM I 52,5R) was used as the cementing agent. The density of the cement grains is 3.15 .

\section{Specimen preparation}

The particle size distribution of the specimens tested was kept constant throughout the study. Because the cement contributed to more fines in the soil, an equal quantity of soil fines to the amount of added cement was subtracted from the cemented specimens. Following this procedure the dry density of the soil was also constant throughout the study even though the cement content changed. The specific gravity of the cement-soil mixture was calculated as a weighted average of the density of the soil $\left(\mathrm{G}_{\mathrm{s}}=2.72\right)$ and that of the cement $\left(\mathrm{G}_{\mathrm{s}}=3.15\right)$, and thus it was different for different cement contents. 
In preparing the specimens, the correct quantities of soil and cement were mixed until reaching uniform consistency, and then water was added while continuing mixing until a homogeneous paste was created. The amount of cement for each mixture was calculated from the mass of the dry soil in order to achieve the desired cement content. The static compaction of the specimens was carried out in three layers in a cylindrical stainless steel mold that had been lubricated. Each layer was slightly scratched for better bonding. At least 12 hours after molding (to prevent swelling) the specimen was extracted from the mold, and its weight and dimensions were measured with accuracies of $0.01 \mathrm{~g}$ and $0.1 \mathrm{~mm}$. They were placed in plastic bags to avoid significant variations of moisture content, and then they were left to cure in a humid room for six days, at $23^{\circ} \pm 2^{\circ} \mathrm{C}$ temperature and $95 \%$ relative humidity. The curing time was set at nine days for all specimens. Thanks to the rapid hardening property of the cement there was no significant gain in strength past the seven days curing, and thus the mechanical behavior of these latter specimens should not have been affected by it.

The cemented specimens were prepared at two different dosages, or molding points, taken from the relationship between unconfined compressive strength $\left(\mathrm{q}_{\mathrm{u}}\right)$ and the adjusted porosity/cement ratio $\left(\mathrm{n} / \mathrm{C}_{\mathrm{iv}}{ }^{0.21}\right)$ expressed in Figure 2, which is detailed in Rios et al. (2009) and Rios (2011). This relationship was obtained with specimens molded with a water content of $12 \%$, determined from the Normal and Modified Proctor curves for cemented soil in Figure 1, but for different densities and cement contents. Adding cement has the effect of decreasing the optimum water content and increasing the maximum dry unit weight (because of the increase in fines content). In this study however, because the quantity of fines was kept constant by replacing soil fines with cement, the effect was minimized and thus specimens with different cement contents should have similar Proctor curves. The two molding points selected for the study were for cemented sand of strengths of $800 \mathrm{kPa}$ and $2,000 \mathrm{kPa}$, of magnitude relevant to practice. As shown in Figure 2, they correspond to adjusted porosity-cement indices 
$\mathrm{n} / \mathrm{C}_{\mathrm{iv}}{ }^{0.21}=36$ and $\mathrm{n} / \mathrm{C}_{\mathrm{iv}}{ }^{0.21}=29$ respectively. Considering the usual economical range of cement contents for soil treatment ranges between 2 and 7\%, four molding conditions were defined, in terms of cement content (see Figure 3): for the higher strength $(2,000 \mathrm{kPa})$, higher cement contents were used (5\% and 7\%) and for the lower strength $(800 \mathrm{kPa})$ the lower bound of the previous range was adopted ( 2 and $4 \%$ ). The corresponding porosities were calculated from the definition of the adjusted porosity/cement ratio. The molding water content was the same in all specimens, chosen as the optimum value obtained in Figure 1 for the soil-cement specimen.

The uncemented specimens were prepared by mixing soil and water at a target moisture content and compacting in layers in a similar way to the cemented specimens to achieve two different compaction degrees. Table 2 summarizes the molding conditions of all the specimens.

\section{Testing procedures}

Isotropic compression tests were performed in the soil mechanics laboratories of Imperial College London (UK). In pure sand, isotropic yield stresses are often reached at pressures well in excess of the pressures available in conventional triaxial apparatus. The same is generally true of cemented sand (Cuccovillo and Coop, 1999). The compression tests were therefore carried out in a 70MPa high pressure apparatus on specimens of $50 \mathrm{~mm}$ diameter and $100 \mathrm{~mm}$ height. Two axial non-submersible LVDTs with exposed contacts were used for local measurement of deformations (Cuccovillo and Coop, 1997). The cell and pore water pressure were measured using pressure transducers of $70 \mathrm{MPa}$ capacity and the variation of volume of the specimen was monitored using a 50cc Imperial College volume gauge.

The specimens were cured for nine days before being placed in water to facilitate saturation, generally for about fifteen hours overnight, then they were put for an additional forty minutes within water in the vacuum chamber. This procedure allowed a degree of 
saturation of $90 \%$ as measured by the weight of the specimen before and after being placed in water. Full saturation was achieved in the triaxial cell, where a B-value of 0.9 was reached for a back pressure of $700 \mathrm{kPa}$.

\section{ISOTROPIC COMPRESSION TEST RESULTS}

Results from the isotropic compression tests are plotted in Figure 4. The compression curves of the cemented sand specimens are initially flat, reflective of the stiffness of the cement but at a stress of about $2 \mathrm{MPa}$ the slope of the curves increases markedly. This sharp yield is the result of damage to the cementitious bonds. The slope progressively reduces until a mean effective stress around $20 \mathrm{MPa}$, where for each adjusted porosity/cement ratio the compression curves for the two different cement contents eventually converge to a unique compression line. This line, which represents the locus of significant breakage of the cement due to isotropic compression, is the normal compression line of the cemented sand (NCL $\left.\mathrm{N}_{\text {cement }}\right)$. The $\mathrm{NCL}_{\text {cement }}$ are distinct for the two dosages and appear to be parallel.

Also shown in Figure 4 are two isotropic compression curves for the uncemented Porto silty sand, which were obtained from specimens molded at two different void ratios and tested in identical conditions as the cemented sand. The soil specimens initially have a stiff response with little volumetric deformation, then the compression curve changes progressively to a steeper slope. At higher stresses the specimens prepared at different initial void ratios converge to a unique normal compression line ( $\left.\mathrm{NCL}_{\text {silty_sand }}\right)$. The NCLs of the cemented specimens for each adjusted porosity/cement ratio do not coincide with the $\mathrm{NCL}_{\text {silty_sand }}$ but are parallel to it, with the curve obtained for the lowest adjusted porosity-cement index plotting to the right of the curve obtained for the higher index. The location of the $\mathrm{NCL}_{\text {cement }}$ to the right of the $\mathrm{NCL}_{\text {silty_sand }}$ suggests that there are still some elements of bonding in the cemented sand even at high stresses. Examination of the specimens of cemented sand after compression to 
40MPa only showed that the cemented soil had broken into aggregates and clusters of smaller size.

Figure 2 indicates that there is a unique value of unconfined compressive strength for each adjusted porosity cement ratio, independently of the cement content. The relationship between unconfined compressive strength and yield stress in cemented clay has been established by previous researchers e.g. Horpibulsuk et al. (2004). Thus, it should be expected that the isotropic yield stress for a given porosity-cement index is also unique. Given the results obtained here, it is proposed that for the sand examined here, there is a family of parallel NCLs

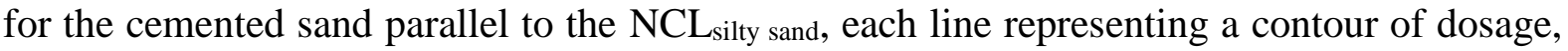
and the lower the adjusted index, the further away the $\mathrm{NCL}_{\text {cement }}$ from the $\mathrm{NCL}_{\text {silty_sand. This }}$ is illustrated in Figure 5 which shows that the higher the cementation bond (corresponding to lower adjusted porosity/cement ratios) the higher is the additional void ratio in relation to the uncemented NCL.

Liu and Carter (2000) proposed a constitutive model to simulate the virgin compression line of naturally structured clays, which tend to be weakly cemented. This model was later used by Suebsuk et al. (2010) to simulate the compression behavior of artificially cemented clays up to high percentages of cement. While natural clays and some cement-treated clays with weaker bonding have comparatively high rates of destructuration and their NCLs converge to the NCL of the reconstituted or uncemented clay at large strains (e.g. Smith et al., 1992; Kasama et al., 2006), in soils with stronger bonding the structure tends to degrade less rapidly, and some elements of bonding can remain even at large stresses, which are sometimes assimilated to fabric. In this case, the NCL of the cemented soil never reaches the NCL of the uncemented soil but a line parallel to it, like the soil presented herein. This behavior can be simulated by constitutive models for structured soils that include effects of fabric and bonding, 
such as the Sensitivity 3-Surface Kinematic Hardening (S3-SKH) model developed by Baudet \& Stallebrass (2004).

\section{CONCLUSIONS}

The most significant aspect of the results presented here is that for a given adjusted porositycement index, there is a unique NCL that is reached at large stresses. The existence of parallel NCLs for different adjusted porosity-cement indices suggests that even at large stresses there are some elements of the cementing that remain. The location of the NCL for a given dosage seems to be linked to the adjusted porosity-cement index, but further research is needed to verify it. The adjusted porosity-cement index was nevertheless demonstrated to be a powerful parameter to describe the behavior of cemented sand in pure compression.

\section{ACKNOWLEDGEMENTS}

The authors wish to thank Professor Coop and the Imperial College team to allow them to carry out the isotropic compression tests when time was pressing. A word of gratitude is also given to the FEUP PhD student Miguel Amaral who has made some additional tests that gave more consistency in the results presented herein. This research was developed under the activities of FCT (Portuguese Foundation for Science and Technology) research unit CEC, in FEUP [PTDC/ECM/ 099475/2008], and financed by the European Community (QREN/UE/FEDER), Operational Program for Competitive Factors "COMPETE". The first author had the financial support of the PhD grant SFRH/ BD / 29346 / 2006. 


\section{REFERENCES}

ASTM (1998). "Standard practice for classification of soils for engineering purposes (Unified Soil Classification System)”. D 2487-98, ASTM.

Baudet, B. A., \& Stallebrass, S. (2004). "A constitutive model of structured clays." Géotechnique, 54(4), 269-278.

Catton, M. D. (1962). “Soil-cement technology - A résumé.” Research and Development Laboratories of the Portland Cement Association: Bulletin 136. Reprinted from the Journal of PCA Research and Development Laboratories, 4(1), 13-21.

Clough, G., Sitar, N., Bachus, R., and Rad, N. (1981). "Cemented sands under static loading." Journal of the Geotechnical Engineering Division, 107(GT6), 799-817.

Consoli, N.C., Rotta, G.V. and Prietto, P.D.M. (2000). "Influence of curing under stress on the triaxial response of cemented soils - technical note.” Géotechnique 50(1), 99-105.

Consoli, N., Foppa, D., Festugato, L. and Heineck, K. (2007). "Key parameters for strength control of artificially cemented soils." Journal of Geotechnical and Geoenvironmental Engineering, 133(2), 197-205.

Consoli, N., Viana da Fonseca, A., Cruz, R.C. and Heineck, K. (2009). "Fundamental Parameters for the Stiffness and Strength Control of Artificially Cemented Sand." Journal of Geotechnical and Geoenvironmental Engineering, 135(9), 1347-1353.

Consoli, N.C., Viana da Fonseca, A., Rios, S., Cruz, R.C. and Fonini, A. (2011). "Parameters controlling stiffness and strength or artificially cemented soils." Géotechnique (in press).

Cuccovillo, T. and Coop, M. R. (1997). “The measurement of local axial strains in triaxial tests using LVDT's." Géotechnique, 47(1), 167-171.

Cuccovillo, T., and Coop, M. (1999). "On the mechanics of structured sands." Géotechnique, $49,741-760$.

Dupas, J. M. and Pecker, A. (1979). "Static and dynamic properties of sand-cement." Journal of the Geotechnical Engineering Division, 105(3), 419-436.

Horpibulsuk, S., Bergado, D.T., and Lorenzo, G.A. (2004). "Compressibility of cement admixed clays at high water content." Géotechnique, 54(2), 151-154. 
Horpibulsuk, S., Miura, N., and Nagaraj, S. (2005). "Clay-Water/Cement Ratio Identity for Cement Admixed Soft Clays." Journal of Geotechnical and Geoenvironmental Engineering, 131, 187-192.

Ingles, O. G. and Metcalf, J. B. (1972). "Soil stabilization-Principles and practice." Butterworths, Australia.

Kasama, K., Zen, K., and Iwataki, K. (2006). "Undrained Shear Strength of Cement Treated Soils.” Soils and Foundations, 46, 221-232.

Liu, M.D., and Carter, J.P. (2000). "Modelling the destructuring of soils during virgin compression." Géotechnique, 50(4): 479-483.

Miura, N., Horpibulsuk, S., and Nagaraj, S. (2001). "Engineering Behaviour of Cement Stabilized Clay at High Water Content.” Soils and Foundations, 41, 33-45.

Porbaha, A., Tanaka, H. and Kobayashi, M. (1998). "State of the art in deep mixing technology. Part II: Applications.” Ground Improvement Journal. ISSMGE, 2(2), 125-139.

Rios, S. (2011). "A general framework for the geomechanical characterisation of artificially cemented soil." $\mathrm{PhD}$ thesis, University of Porto, Portugal.

Rios, S., Viana da Fonseca, A. and Consoli, N.C. (2009). "Strength and stiffness properties of mixtures of granitic soil-cement.” Proc. XVIIth ICSMFE Conference, Egypt.

Rotta, G. V., Consoli, N. C., Prietto, P. D. M., Coop, M. R. and Graham, J. (2003). "Isotropic yielding in an artificially cemented soil cured under stress." Géotechnique 53(5), 493-501.

Suebsuk, J., Horpibulsuk, S., \& Liu, M. D. (2010). "Modified Structured Cam Clay: A generalised critical state model for destructured, naturally structured and artificially structured clays." Computers and Geotechnics, 37(7-8), 956-968.

Thomé, A., Donato, M., Consoli, N. C. and Graham, J. (2005). "Circular footings on a cemented layer above weak foundation soil.” Can. Geotech. J., 42, 1569-1584.

Viana da Fonseca, A., Carvalho, J., Ferreira, C., Santos, J.A., Almeida, F., Pereira, E., Feliciano, J., Grade, J. and Oliveira, A. (2006). "Characterization of a profile of residual soil from granite combining geological, geophysical and mechanical testing techniques." Geotechnical and Geological Engineering, 24, 1307-1348.

Viana da Fonseca, A., Caberlon, R. and Consoli, N. C. (2009). "Strength properties of sandy soil-cement admixtures.” Geotechnical and Geological Engineering. 27(6), 681-686. 


\section{LIST OF TABLES AND FIGURES}

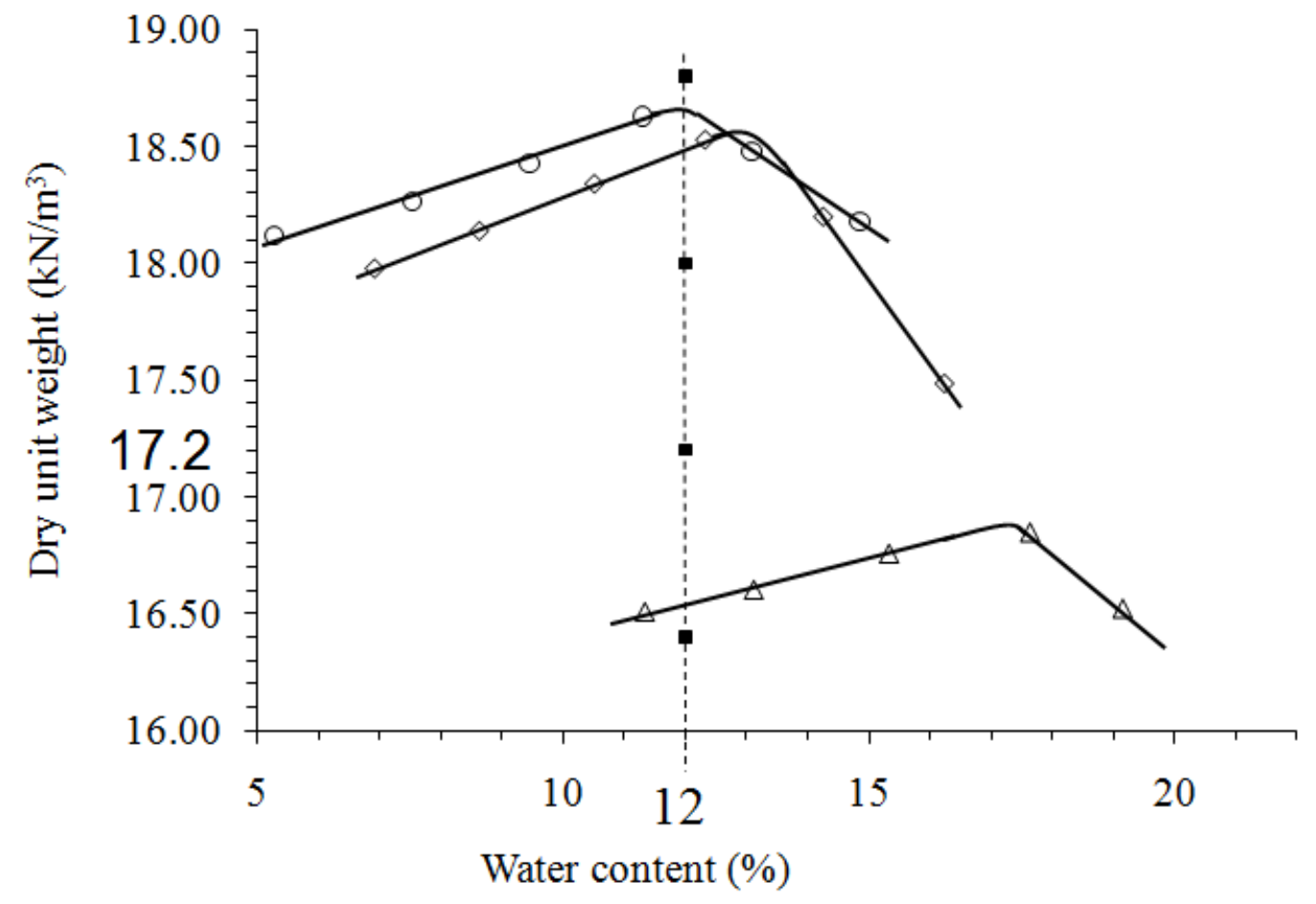
$\triangle$ Normal Proctor- Soil
$\diamond$ Modified Proctor- Soil
o Modified Proctor- Soil-cement
- MouldingPoints

FIGURE 1 - Normal and Modified Proctor curves for the uncemented and cemented soil with $3 \%$ of cement content. 


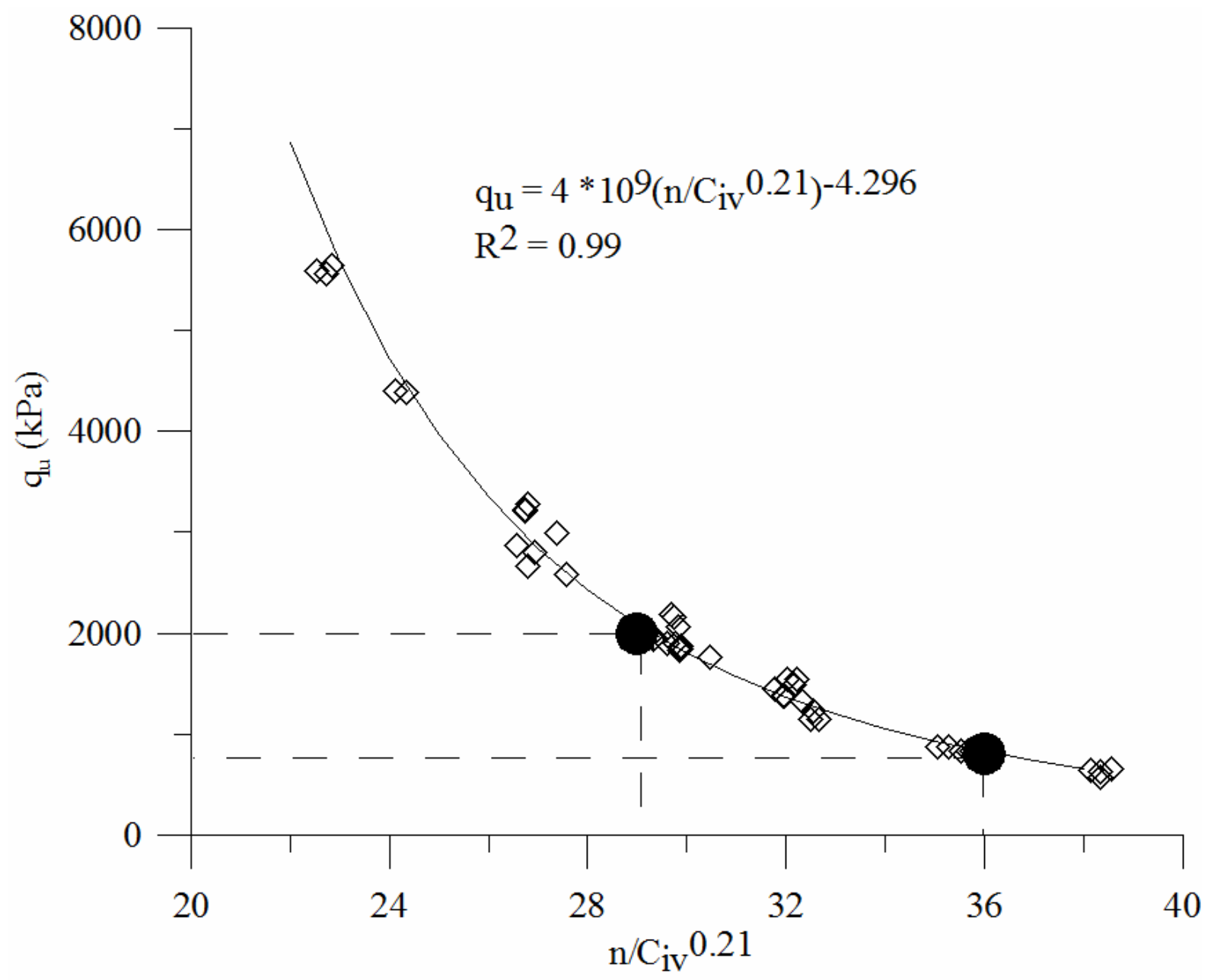

FIGURE 2 - Determination of molding conditions (data from Rios et al., 2009).

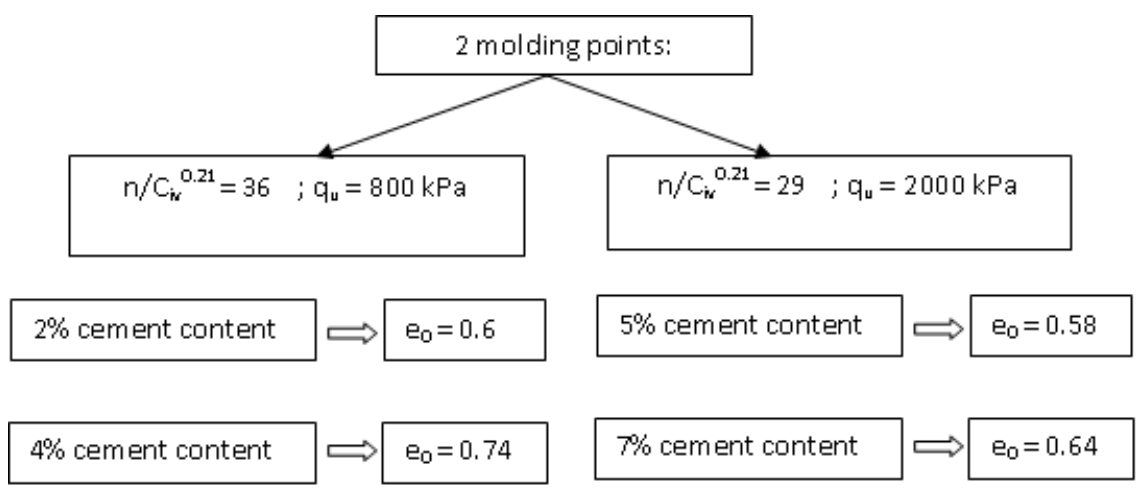

FIGURE 3 - Chart of the molding conditions. 


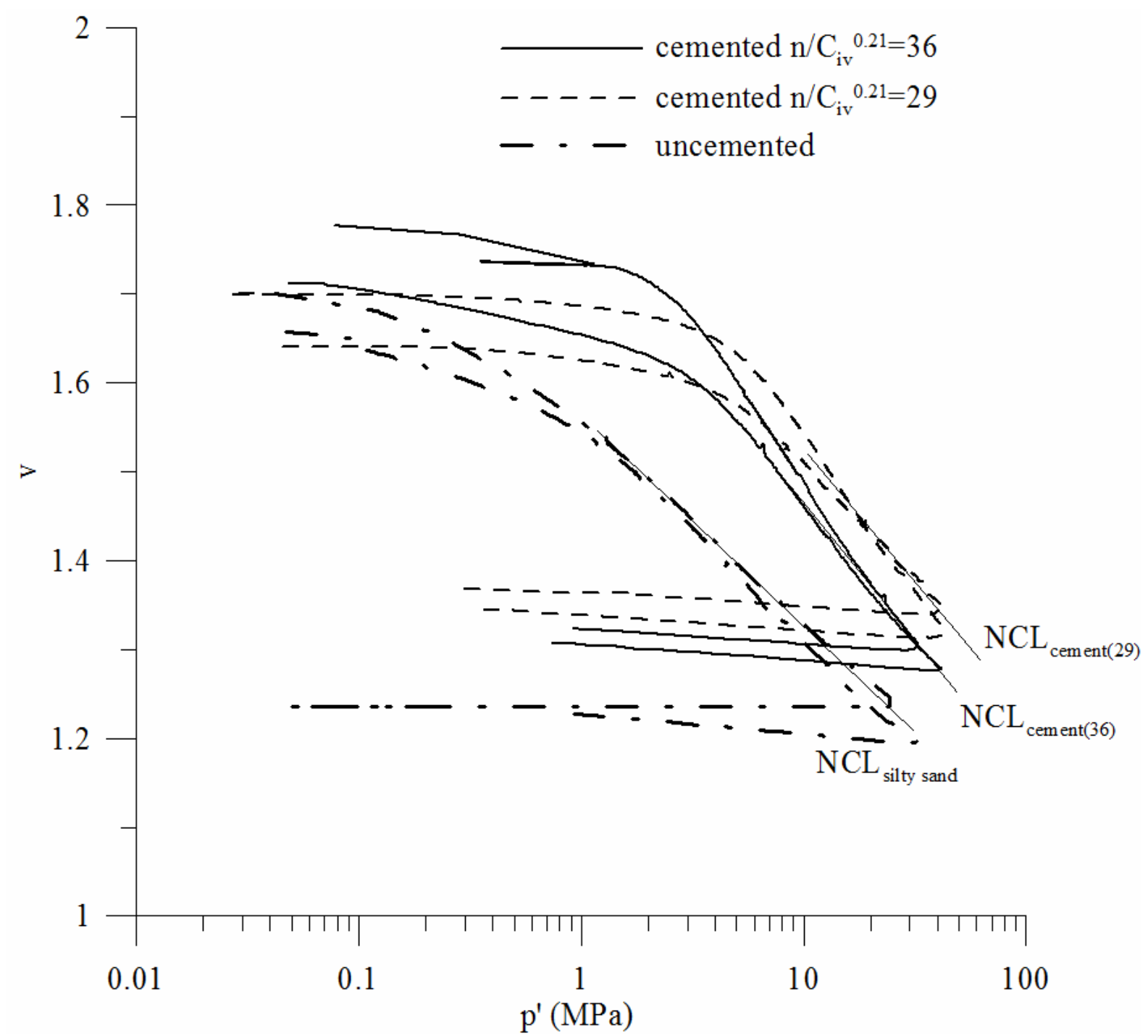

FIGURE 4 - Isotropic compression data and normal compression lines (NCL) for the clean silty sand and cemented silty sand. 


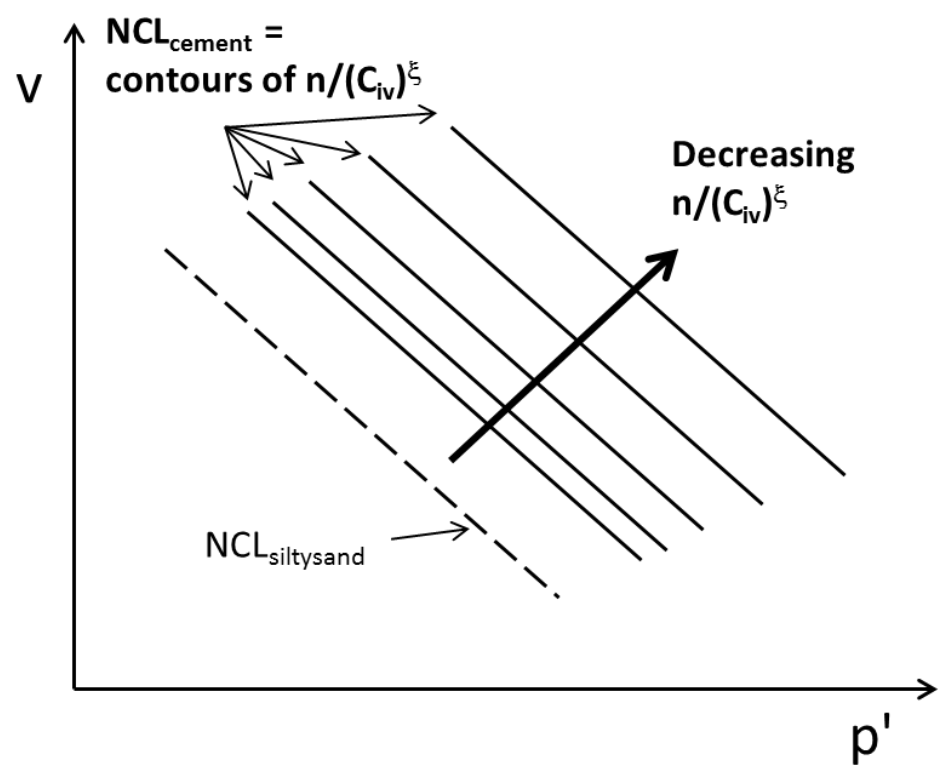

FIGURE 5 - Normal compression lines for cemented sand of given adjusted porosity-cement index. 
TABLE 1 - Properties of Porto residual silty sand.

\begin{tabular}{lllllllll}
\hline $\mathrm{G}_{\mathrm{s}}$ & $\begin{array}{l}\mathrm{D}_{10} \\
(\mathrm{~mm})\end{array}$ & $\begin{array}{l}\mathrm{D}_{30} \\
(\mathrm{~mm})\end{array}$ & $\begin{array}{l}\mathrm{D}_{50} \\
(\mathrm{~mm})\end{array}$ & $\begin{array}{l}\mathrm{D}_{60} \\
(\mathrm{~mm})\end{array}$ & $\mathrm{C}_{\mathrm{u}}$ & $\mathrm{C}_{\mathrm{c}}$ & $\omega_{\mathrm{L}}$ & $\omega_{\mathrm{P}}$ \\
\hline 2.72 & 0.003 & 0.055 & 0.25 & 0.4 & 113 & 2.72 & $34 \%$ & $31 \%$ \\
\hline
\end{tabular}

TABLE 2 - Programme of isotropic compression tests.

\begin{tabular}{cccccc} 
Cement content & $\begin{array}{c}\text { Molding dry } \\
\text { unit weight } \\
\mathrm{kN} / \mathrm{m}^{3}\end{array}$ & $\begin{array}{c}\text { Molding void } \\
\text { ratio }\end{array}$ & $\begin{array}{c}\text { Molding water } \\
\text { content }\end{array}$ & $\begin{array}{c}\text { Adjusted void } \\
\text { cement ratio } \\
\mathrm{n} / \mathrm{C}_{\mathrm{iv}}{ }^{0.21}\end{array}$ & UCS \\
\hline 0 & 15.4 & 0.81 & 12 & - & - \\
0 & 17 & 0.66 & 12 & - & - \\
2 & 16.7 & 0.6 & 12 & 36 & 800 \\
4 & 15.4 & 0.74 & 12 & 36 & 800 \\
5 & 17 & 0.58 & 12 & 29 & 2000 \\
7 & 16.4 & 0.64 & 12 & 29 & 2000
\end{tabular}

